\title{
Reduce disease by improving environmental health
}

A cleaner, greener Canada could save billions on health care and prevent thousands of premature deaths each year, according to environmental lawyer David Boyd.

The World Health Organization (WHO) estimates that exposure to toxic substances in air, water, food and consumer goods causes $13 \%$ of all disease and more than 30000 premature deaths in Canada each year. These health impacts are "almost entirely preventable through intelligent public policy," said Boyd at the October launch of Cleaner, Greener, Healthier: a Prescription for Stronger Canadian Environmental Laws and Policies.

In his book, Boyd compares environmental policies across Canada, the United States, Australia and 28 members of the European Union (EU).

Reducing pollution could save Canadians \$3.6-\$9.1 billion a year in costs associated with respiratory disease, cardiovascular illness, cancer and congenital disorders, he said. Yet Canada consistently lags behind peers when it comes to regulating air pollution, water contaminants and other environmental health hazards.

"Even our voluntary guidelines are less stringent than legally binding standards in these other jurisdictions," Boyd said.

Differing international guidelines on sulphur dioxide, a toxic gas that can cause heart and lung disease, are a case in point. Canada's voluntary guideline for acceptable sulphur dioxide emissions is 334 parts per billion per hour. That's almost five times less stringent than the binding American standard of 75 parts per billion per hour and "light years away" from the $20 \mu \mathrm{g} / \mathrm{m}^{3}$ or 7.6 parts per billion per day recommend by WHO, said Boyd.

Meanwhile, Canada consistently ranks among the top emitters per capita of air pollution and greenhouse

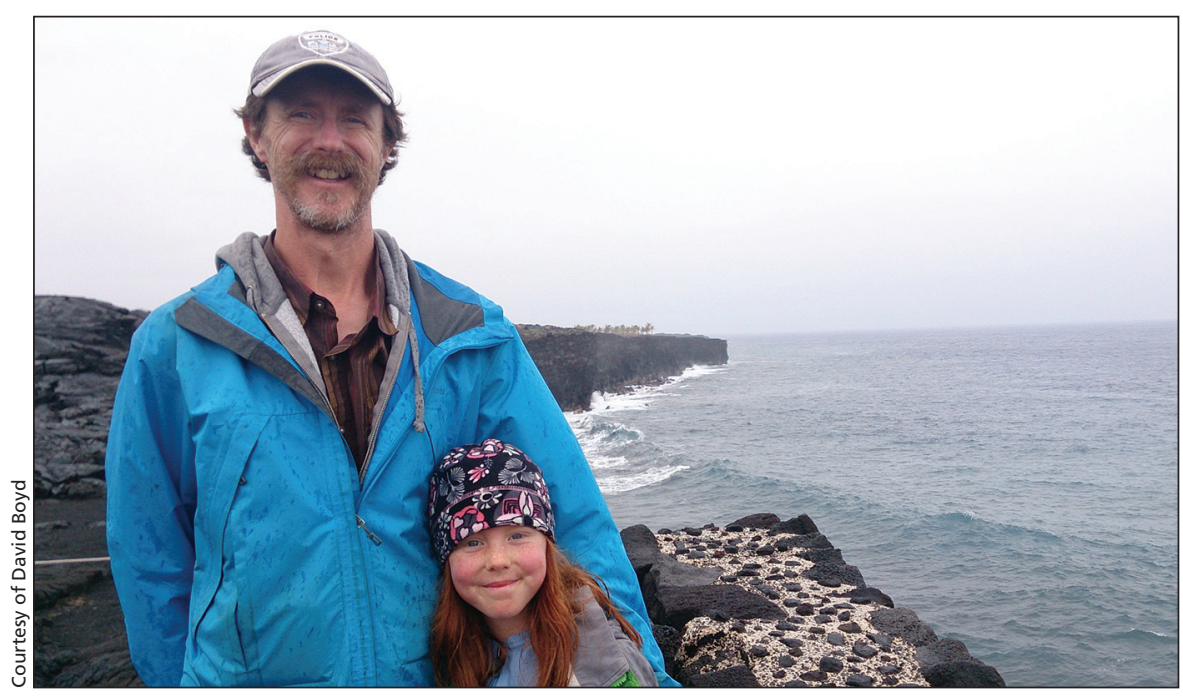

Environmental lawyer David Boyd warns that lax environmental protections jeopardize human health.

gases in the Organisation for Economic Co-operation and Development (OECD).

The disparity between Canadian and international standards for drinking water are even more striking, said Boyd. In a comparison of limits on 67 contaminants, European standards range from 50 to 1000 times stronger than Canadian guidelines.

The EU's proactive approach to potentially harmful substances is also reflected in the regulation of pesticides, said Boyd. "There are more than 40 ingredients used in more than 1000 pesticides for sale in Canada today that could not be sold in the EU because of health concerns."

Canadian governments have tended to take a more conservative wait-and-see approach because of economic concerns, Boyd explained. However, this approach may be short-sighted given that more than 1 in 10 cases of illness in Canada can be attributed to environmental risk factors. "We're in danger of having the health care budget cannibalize the environment budget, which in turn will expose more people to environmen- tal hazards, further burdening the health system," he said.

According to a July CMAJ editorial, "to address this health issue, Canada must adopt and enforce the WHO guidelines in all jurisdictions and improve monitoring of our air quality."

Boyd noted that going green shouldn't land governments in the red. According to global accounting firm KPMG, Canada doesn't use taxation to address pollution as much as other developed nations and even some developing nations, including China and South Africa. Boyd argues this is an untapped source of revenue for stronger environmental protections.

"Canada only gets about $4 \%$ of government revenue from green taxes compared to leading European countries which get about $10 \%$," he said. "Raising the level of environmental taxation in Canada to the OECD average could generate over $\$ 8$ billion a year in additional revenue; raising it to the European average would generate $\$ 20$ billion a year." - Lauren Vogel, CMAJ

CMAJ 2015. DOI:10.1503/cmaj.109-5185 